\title{
28 EFFECTIVE PRACTICE: AN IMMEDIATE COLLABORATIVE RESPONSE TO PREVENT FURTHER NET FISHING DROWNING AMONG PACIFIC PEOPLES
}

doi:10.1136/injuryprev-2012-040580f.28

S Harrop, H Aonga. WaterSafe Auckland, PO Box 8163, Symonds Street, Auckland 1150

Background Recreational fishing often provides a valuable and relatively cheap food source for many Pacific families. While land- and boat-based fishing in New Zealand have benefitted from safety interventions in recent years, the practice of net fishing at beach and harbours has not. Net fishing in New Zealand waters is often more dangerous than those waters in the Pacific Islands and some Pacific Island net fishing methods are inappropriate here. In response to five Pacific drowning fatalities related to net fishing off Auckland's dangerous west coast beaches in October 2011, WaterSafe Auckland called a meeting of key stakeholders and instigated a collaborative project to address safety issues surrounding these fatalities.

Methods Key partners Surf Life Saving, Auckland Council, Pasifika Injury Prevention Aukilana (PIPA), ACC, the Ministry of Pacific Island Affairs, Pacific Island Advisory Panel, community net fishing expert and WaterSafe Auckland agreed to initiate a collaborative project with key short term outcomes for the 2011/2012 summer season.

Results Water safety education for net fishing was developed and delivered via a number of channels including Pacific and mainstream media, Pacific events and Church ministers. Ministers were requested to highlight and promote safe net fishing practices and the use of lifejackets. Lifejackets were given to Ministers to wear and distribute at their discretion. The results will be evaluated and used to make recommendations for an ongoing project.

Conclusions By working collaboratively, key partners can utilise their expertise quickly and effectively to address death by drowning for specific target activities and communities. 